\title{
Kinetic evaluation of the size-dependent decomposition performance of solvent-free microcellular polylactic acid foams
}

\author{
GUO GePu ${ }^{1}$, MA Qing $\mathrm{Yu}^{1 *}$, WANG Fang ${ }^{2}$, ZHAO Bo ${ }^{3} \&$ ZHANG Dong ${ }^{4}$ \\ ${ }^{1}$ Key Laboratory of Optoelectronics of Jiangsu Province, School of Physics and Technology, Nanjing Normal University, Nanjing 210046, China; \\ ${ }^{2}$ Center of Analysis and Testing, Nanjing Normal University, Nanjing 210046, China; \\ ${ }^{3}$ College of Chemistry and Materials Science, Nanjing Normal University, Nanjing 210046, China; \\ ${ }^{4}$ Institute of Acoustics, Key Laboratory of Modern Acoustics, Ministry of Education, Nanjing University, Nanjing 210093, China
}

Received May 28, 2011; accepted July 24, 2011

\begin{abstract}
A thermal gravimetric method is described for evaluating the kinetics of cell size-dependent decomposition and lifetime estimation for microcellular tissue engineering scaffolds made of biodegradable polylactic acid (PLA) foams. PLA foam cell sizes from 550 to $20 \mu \mathrm{m}$ were fabricated experimentally using a solvent-free solid-state foaming technique under saturation pressures from 1 to $5 \mathrm{MPa}$. The thermal properties of the PLA foams with respect to the cell sizes were measured using thermal gravimetric analysis in a nitrogen atmosphere and the activation energy and pre-exponential factor were derived to evaluate the decomposition kinetics and estimate lifetime. It was found that small cell sizes can be achieved under high saturation pressures and that the thermal stability of PLA decreases after the fabrication process. The cell size-dependent thermal stability and degradation rate indicate that a PLA foam of larger cell sizes has a shorter degradation time, a few tenths that of the PLA raw material, at a temperature of $37^{\circ} \mathrm{C}$. The results suggest that it is feasible to optimize fabrication parameters to obtain appropriate cell sizes and lifetimes that satisfy the application requirements for various organs. This study provides the basis for precise scaffold design and quantitative analysis of PLA foams in tissue engineering applications.
\end{abstract}

tissue engineering scaffold, PLA foam, cell size, thermal gravimetric analysis, decomposition kinetic performance

Citation: Guo G P, Ma Q Y, Wang F, et al. Kinetic evaluation of the size-dependent decomposition performance of solvent-free microcellular polylactic acid foams. Chin Sci Bull, 2012, 57: 83-89, doi: 10.1007/s11434-011-4873-5

Tissue engineering applies the principles of engineering and the life sciences to replace diseased or damaged organs and to restore the functionality of these organs without having to subsequently remove the scaffold [1]. To maintain the tissuespecific function of the cells, a 3-D substrate called a tissue engineering scaffold (TES) [2,3] should be inserted to retain the organ's shape and structure for cell growth and nutrient diffusion. To encourage tissues to grow towards the specific direction of the prefabricated 3-D frame, an ideal TES should have the characteristics [4] of an appropriate degradation rate, good biocompatibility, favorable plasticity and well-distributed cell sizes that are suitable for cell attachment and tissue growth.

*Corresponding author (email: maqingyu@njnu.edu.cn)
PLA is a renewable and biodegradable material that can be degraded by hydrolysis into products that can be metabolized and excreted [5]. In recent years, several techniques, such as copolymerization, grafting and blending, have been explored with the aim of reducing the regularity and crystallinity of the PLA molecular chains to improve flexibility and elasticity. The degradation performance, hydrophilicity and the mechanical characteristics of PLA have also been improved to meet the demands of medical applications [6]. McNeill and Leiper [7,8] investigated the degradation of PLA under programmed and isothermal heating conditions and reported that the main products in the pyrolysis were cyclic oligomers (including lactides) and some low boiling point products, including carbon dioxide, acetaldehyde, ketene and carbon monoxide. A multi-step process for 
PLLA pyrolysis performed by Kopinke $[9,10]$ showed that intra-molecular transesterification was a dominant degradation pathway and that pyrolysis behavior differed between pure and Sn-containing PLLAs.

Although PLA is brittle and has poor impact resilience, these properties can be improved through a microcellular foaming technique and it has attracted increasing attention for use as biodegradable medical materials. Previous research has mainly focused on the thermal decomposition performance and evaluation of hydrophilicity and biocompatibility for PLA raw materials and its mixed polymers, while little work has been reported on the effects of microstructure on decomposition kinetics of fabricated PLA foams. To form highly porous biodegradable TES, several fabrication techniques have been investigated over the past few decades, such as the fiber bonding [11], solvent casting/particulate leaching [12], salt extraction and gas foaming/particulate leaching [13]. However, most of the methods require either the use of organic solvents or particulate leaching, which could reduce the biocompatibility with regard to tissue regeneration because of residual solvent or particulates. A solvent-free, solid-state gas foaming process using an inert gas such as $\mathrm{N}_{2}$ or $\mathrm{CO}_{2}$ was developed to produce amorphous, semi-crystalline, microcellular PLA foams for TES applications $[14,15]$.

It should be noted that the mechanical and morphological properties of the fabricated TES are mainly determined by the micro-structure, porosity and cell size distribution as well as the specific area, which has a strong impact on the regeneration rate. In practice, the cell size distribution of a TES is determined by the target cells or organs because of variations in cell dimensions. If the cell size is too small, the cell regeneration and tissue reproduction process would be retarded. Inadequate mechanical strength of the TES could result from an excessively large cell size, lowering the efficiency of cell attachment. Therefore, quantitative control of cell size and density is of critical significance for TES fabrication. Although scanning electron microscopy (SEM) has been used to analyze the morphological properties of fabricated PLA foams, it provides only an image of the scanned layer or the surface structure of the specimen rather than the overall integrated tissue reproduction and PLA degradation behaviors [16]. Thermal gravimetric analysis (TGA) [17] is a classical analytical technique that measures the weight change of a material as a function of temperature due to the chemical reactions of gas liberation or atmospheric absorption. Knowledge of decomposition kinetics [18] offers a rapid alternative to accelerate aging tests for evaluation of lifetime, material composition, oxidation, dehydration and corresponding kinetic constants for exploring the relation between the thermal behavior and microstructure [19].

In this study, a solvent-free, solid-state foaming system was developed and PLA foams with various cell sizes and cell densities were fabricated under various saturation pressures, in good agreement with the theory for the dependence of the classical free energy exponential on pressure. Thermal gravimetric measurement was conducted to evaluate the cell size-dependent decomposition kinetics and to estimate the lifetime of microcellular PLA foams. It is shown that a small cell size can be achieved under a high saturation pressure and that stability can be decreased by fabrication at a reduced activation energy. PLA foams with a smaller cell size had a longer degradation time at a temperature of $37^{\circ} \mathrm{C}$. The results suggest that it is feasible to optimize fabrication parameters to generate appropriate cell sizes and lifetimes to satisfy the requirements of applications for specific organs. It also provides a basis for precise scaffold design and quantitative analysis of PLA foams to promote its use in practical tissue engineering applications.

\section{Materials and methods}

\subsection{PLA foam fabrication}

The typical solid-state microcellular foaming process for TES fabrication includes two stages [20,21]. In the first stage, the PLA sample is placed in a $\mathrm{CO}_{2}$ pressure vessel at room temperature and the saturation pressure is adjusted from atmospheric pressure to about $6 \mathrm{MPa}$. The $\mathrm{CO}_{2}$ gas molecules then diffuse over time into the free spaces within the PLA molecular structure until attaining the saturation concentration. The saturated PLA sample can be considered to undergo typical homogeneous nucleation [22] and each $\mathrm{CO}_{2}$ gas molecule can be treated as a microcellular nucleation point. When the PLA sample is removed from the pressure vessel to atmospheric pressure, the supersaturated sample becomes unstable because of the excess dissolved gas. With gas desorption for a period of time, cell nucleation reaches a dynamic equilibrium with the homogeneous gas distribution inside the PLA sample. In the second stage, when the foaming temperature is higher than the glass transition temperature of the PLA material, cell nucleation grows rapidly because of the volume expansion of the supersaturated $\mathrm{CO}_{2}$ until gas pressure equilibrium is reached and the PLA foams are then fabricated.

A scanning electron microscope (JSM-5610LV, designed by JEOL Ltd., Tokyo, Japan) was used to investigate the microstructure of the fabricated PLA foams. Image processing software (ACT-2U image software) was used to analyze the cell size distribution and the average cell sizes were measured from the SEM images by the Feret's diameter [22]. PLA raw material including $99.5 \%$ of poly-L-lactic acid (PLLA) and $0.5 \%$ poly-D-lactic acid (PLDA) for solvent-free, solid-state foaming was obtained from Shenzhen Xinsheng New Material Ltd. (Shenzhen, China). The PLA sample was in thin sheet form with the thickness of $0.4 \mathrm{~mm}$ and a density of about $1.25 \mathrm{~g} / \mathrm{cm}^{3}$. The melting temperature and the glass transition temperature were approximately 175 and $63^{\circ} \mathrm{C}$, respectively. Medical, high-purity $\mathrm{CO}_{2}$ gas was bought from Nanjing Airgas Medical, Inc. (Nanjing, China). 


\subsection{Thermal gravimetric measurement}

Thermal gravimetric (TG) experiments were performed on PLA specimens using a thermo-gravimetric analyzer (Pyris 1 TGA, Perkin-Elmer) to investigate decomposition stability. The PLA raw material and PLA foams with a range of cell sizes fabricated at several saturation pressures were heated from room temperature to $500^{\circ} \mathrm{C}$ at various linear heating rates under nitrogen purge gas at a flow rate of $50 \mathrm{~mL} / \mathrm{min}$. The data were analyzed using the Perkin-Elmer Pyris software.

Activation energy [23], which describes the averaged energy difference between activating molecules and reactant molecules, is defined as the minimum amount of energy needed to initiate a chemical process and can reflect the chemical reaction speed. The experimental TG curves of the PLA specimens can be used to calculate the activation energy and estimate the lifetime for degradation performance evaluation based on Toop's method. The dynamic activation energies can be calculated with the Kissinger equation [24]:

$$
\ln \left(\frac{\beta}{T_{\mathrm{p}}^{2}}\right)=\ln \left(\frac{A R}{E}\right)-\frac{E}{R T_{\mathrm{p}}},
$$

and the Ozawa-Doyle equation [25,26]:

$$
\log \beta=\log \left[\frac{A E}{R G(\alpha)}\right]-\frac{0.4567 E}{R T}-2.315,
$$

where $\beta$ is the linear heating rate and $R$ is the molar gas constant, $T$ is the absolute temperature, $T_{\mathrm{p}}$ is the peak temperature of the differential of each TG curve, $A$ is the pre-exponential factor, $E$ is the activation energy, $\alpha$ is the decomposition level and $G(\alpha)$ is the corresponding integral function.

Once the activation energy is known, decomposition kinetics analyses can be performed and the isothermal conversion time of each PLA specimen at a specific temperature $T_{\mathrm{H}}$ for a particular decomposition level $\alpha$ can be estimated based on

$$
\lg t \cong \lg \left(\frac{E}{\beta R}\right)-2.315+\frac{E}{2.303 R T_{\mathrm{H}}}-0.4567 \frac{E}{R T} .
$$

\section{Experimental results}

\subsection{Fabrication results}

Opaque PLA foams were obtained by the fabrication process described above, with volume expansions of over 10 times. Figure 1 shows the images of PLA foams fabricated at saturation pressures of 2 and $4 \mathrm{MPa}$ at a foaming temperature of $90^{\circ} \mathrm{C}$, with measured average cell sizes of 294 and $32 \mu \mathrm{m}$, respectively.

As we know, knowledge of the structural morphological

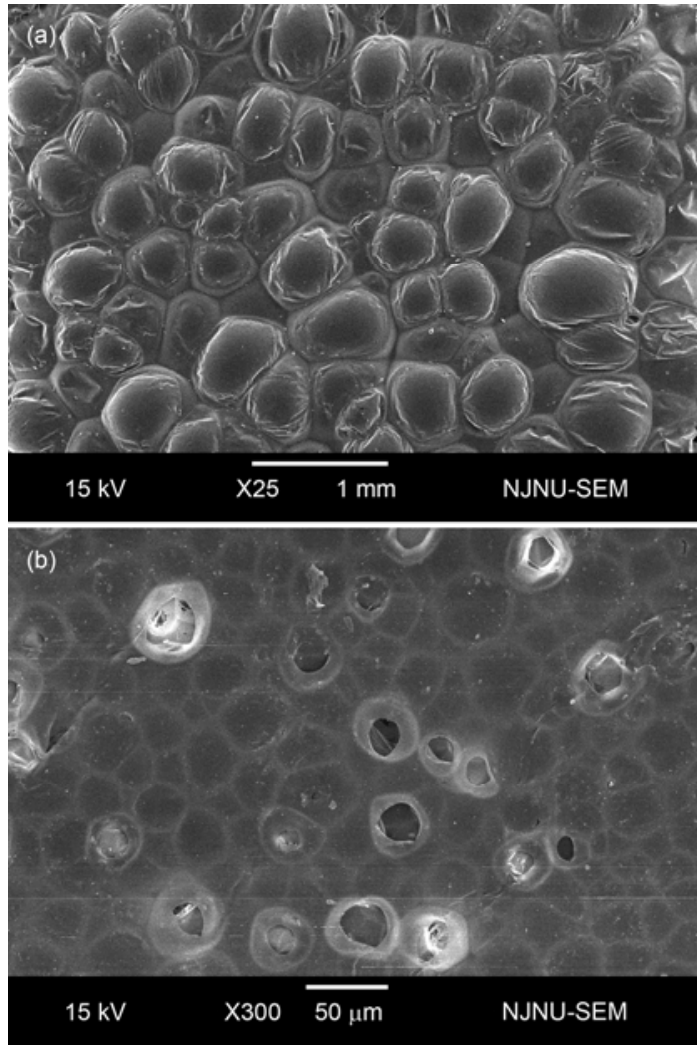

Figure 1 SEM images of PLA foams. (a) Saturation pressure $2 \mathrm{MPa}$, saturation time $48 \mathrm{~h}$; (b) saturation pressure $4 \mathrm{MPa}$, saturation time $24 \mathrm{~h}$.

properties (cell size, cell density, relative density) of fabricated foams are essential for performance evaluation of the thermal and degradation behaviors in tissue engineering applications. In the solid state foaming process, cell nucleation is mainly determined by the saturation pressure and the foaming temperature has the most significant effect on cell expansion [17]. To observe the cell size distribution of the PLA foams as a function of saturation pressure, the PLA samples were placed into a pressure vessel at saturation pressures ranging from 1 to $5 \mathrm{MPa}$. After sufficient time to allow pressure saturation and $30 \mathrm{~min}$ of gas desorption, the PLA samples were foamed at a specific temperature of $90^{\circ} \mathrm{C}$ for $20 \mathrm{~s}$ and the average cell sizes of the fabricated foams were measured with SEM. Figure 2 shows the cell sizes of the foams as a function of saturation pressure, where the measured data are plotted as points and the corresponding exponential fitting curve (solid line) is provided for reference. The results indicate that the saturation pressure has a significant effect on cell size distribution. The cell size decreased from about 550 to $20 \mu \mathrm{m}$ as the saturation pressure increased from 1 to $5 \mathrm{MPa}$. A rapid decrease in cell size was observed when the saturation pressure was below $3 \mathrm{MPa}$, and the cell size was less than $30 \mu \mathrm{m}$ at saturation pressures above $4 \mathrm{MPa}$.

The relation between the cell size $D$ and the saturation pressure $p(\mathrm{MPa})$ can be derived through the exponential 


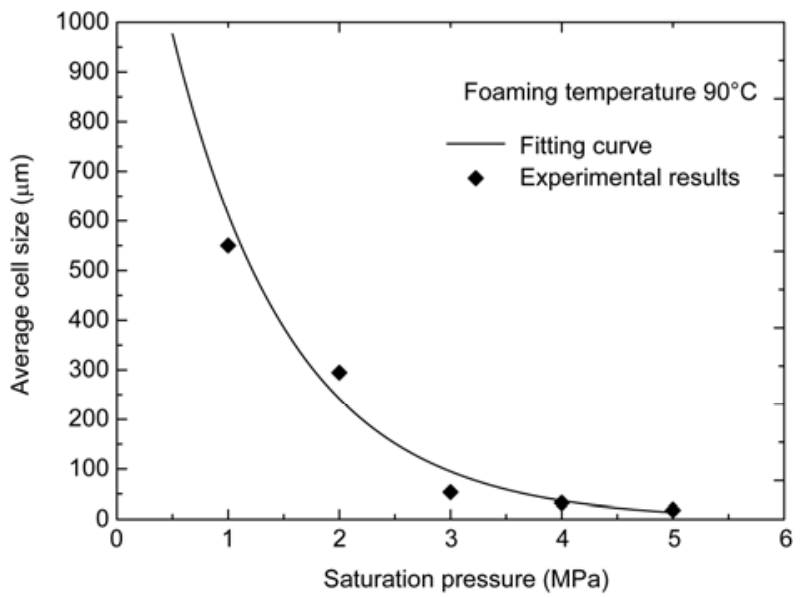

Figure 2 Cell size dependence on saturation pressure.

fitting as

$$
D=D_{T} \exp (-p)
$$

where $D_{T} \approx 1500$ corresponds to a foaming temperature of $90^{\circ} \mathrm{C}$, with units of $\mu \mathrm{m}$. Eq. (4) is in good agreement with the classical free energy exponential dependence of cell size on saturation pressure [22].

Table 1 shows the properties of PLA foams fabricated at several saturation pressures. The approximate cell size was calculated using eq. (4) and the corresponding cell density and specific surface area were also obtained for a foam volume of $1 \mathrm{~cm}^{3}$. It can be seen that smaller cell-sized foams have enhanced cell density, with larger specific surface areas and thinner cell walls. For example, the cell density and specific surface area of the $5 \mathrm{MPa}$ PLA foam (cell size about $20 \mu \mathrm{m}$ ) were, respectively, about 20000 and 25 times those of the $1 \mathrm{MPa}$ PLA foam (cell size about $550 \mu \mathrm{m}$ ). Therefore, higher nucleation of higher saturation pressure produces smaller cells with higher cell density and thinner cell walls. For example, the cell wall thicknesses were about 8.4 and $0.7 \mu \mathrm{m}$ for $1 \mathrm{MPa}$ and $5 \mathrm{MPa}$ PLA foams, respectively. Examples of images are shown in Figure 1, where cell surface damage can be seen in the 4 MPa PLA foam because of the thin cell walls, while the cell surface of the 2 MPa PLA foam are intact.

Table 1 Structural morphological properties of the fabricated PLA foams

\begin{tabular}{ccccc}
\hline $\begin{array}{c}\text { Saturation } \\
\text { pressure } \\
(\mathrm{MPa})\end{array}$ & $\begin{array}{c}\text { Cell size } \\
(\mu \mathrm{m})\end{array}$ & $\begin{array}{c}\text { Cell density } \\
\left(\text { cells } / \mathrm{cm}^{3}\right)\end{array}$ & $\begin{array}{c}\text { Specific } \\
\text { surface area } \\
\left(\mathrm{cm}^{2} / \mathrm{cm}^{3}\right)\end{array}$ & $\begin{array}{c}\text { Cell wall } \\
\text { thickness } \\
(\mu \mathrm{m})\end{array}$ \\
\hline 1 & 550 & $1.15 \times 10^{4}$ & 119 & 8.4 \\
2 & 300 & $7.07 \times 10^{4}$ & 200 & 7.5 \\
3 & 50 & $1.53 \times 10^{7}$ & 1200 & 1.3 \\
4 & 30 & $7.07 \times 10^{7}$ & 2000 & 0.9 \\
5 & 20 & $2.39 \times 10^{8}$ & 3000 & 0.7 \\
\hline
\end{tabular}

\subsection{Decomposition kinetic performance evaluation results}

Figure 3 shows the TG curves of PLA foams fabricated under several saturation pressures at a heating rate of $20^{\circ} \mathrm{C} / \mathrm{min}$. Through differential analysis of the TG curves for the 2, 3 and 4.7 MPa foams, their onset temperatures were obtained as $349.6,341.9$ and $326.5^{\circ} \mathrm{C}$, respectively. The higher onset temperature of $359.5^{\circ} \mathrm{C}$ of the PLA raw material indicates that the onset temperature decreases after the foaming process. At higher saturation pressure, stronger cell nucleation weakens the bonding state of PLA molecules, giving enhanced cell density and thin cell walls, which would reduce the onset temperature.

Figure 4 illustrates the TG curves of the PLA raw material and PLA foams fabricated under saturation pressures of 2, 3 and 4.7 $\mathrm{MPa}$ at heating rates of 5, 10, 20, 30 and $40^{\circ} \mathrm{C} / \mathrm{min}$. The onset temperature for each specimen increased as the heating rate increased, reflecting similar time-temperature dependency to the decomposition reaction. Figure 5 plots the onset temperatures calculated from the TG curves in Figure 4 as points, with the linear fitting curves (solid lines) provided for reference. It is concluded that PLA foams with small cell sizes, fabricated at high saturation pressure, have lower onset temperatures than those with larger cell sizes at the same heating rate. The similar slopes of the linear fit lines at the five heating rates indicate similar dynamic thermal properties of the PLA specimens. This will be useful for precise a priori estimation of the cell size that will result from a given saturation pressure so as to achieve optimal structures during TES fabrication.

Table 2 lists the activation energies and pre-exponential factors for the PLA specimens calculated from eqs. (1) and (2). It can be seen that the activation energies calculated using the Kissinger and Ozawa-Doyle methods were similar for each specimen. The PLA foam fabricated at lower saturation pressure shows lower activation energy, indicating rapid decomposition and absorption by biological tissues. PLA foams with smaller cell sizes, fabricated at higher

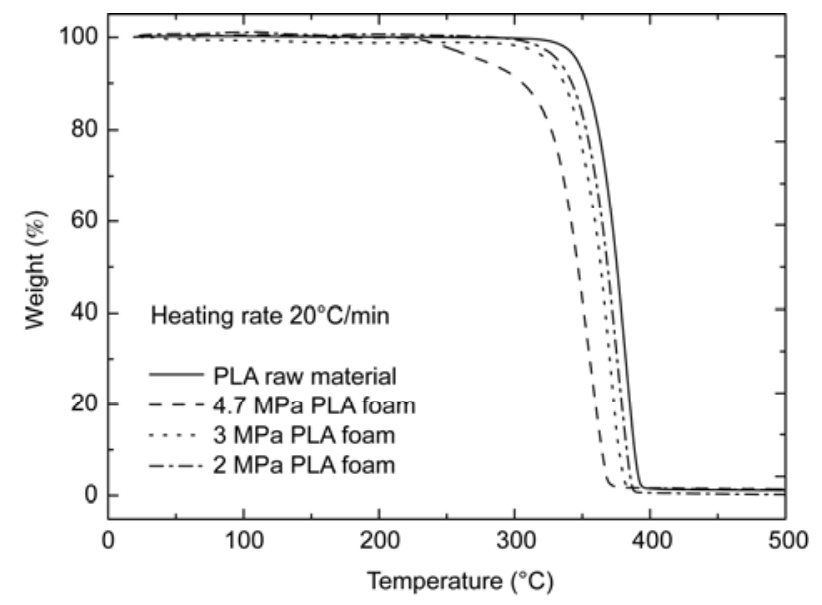

Figure 3 TG curves of the PLA specimens. 

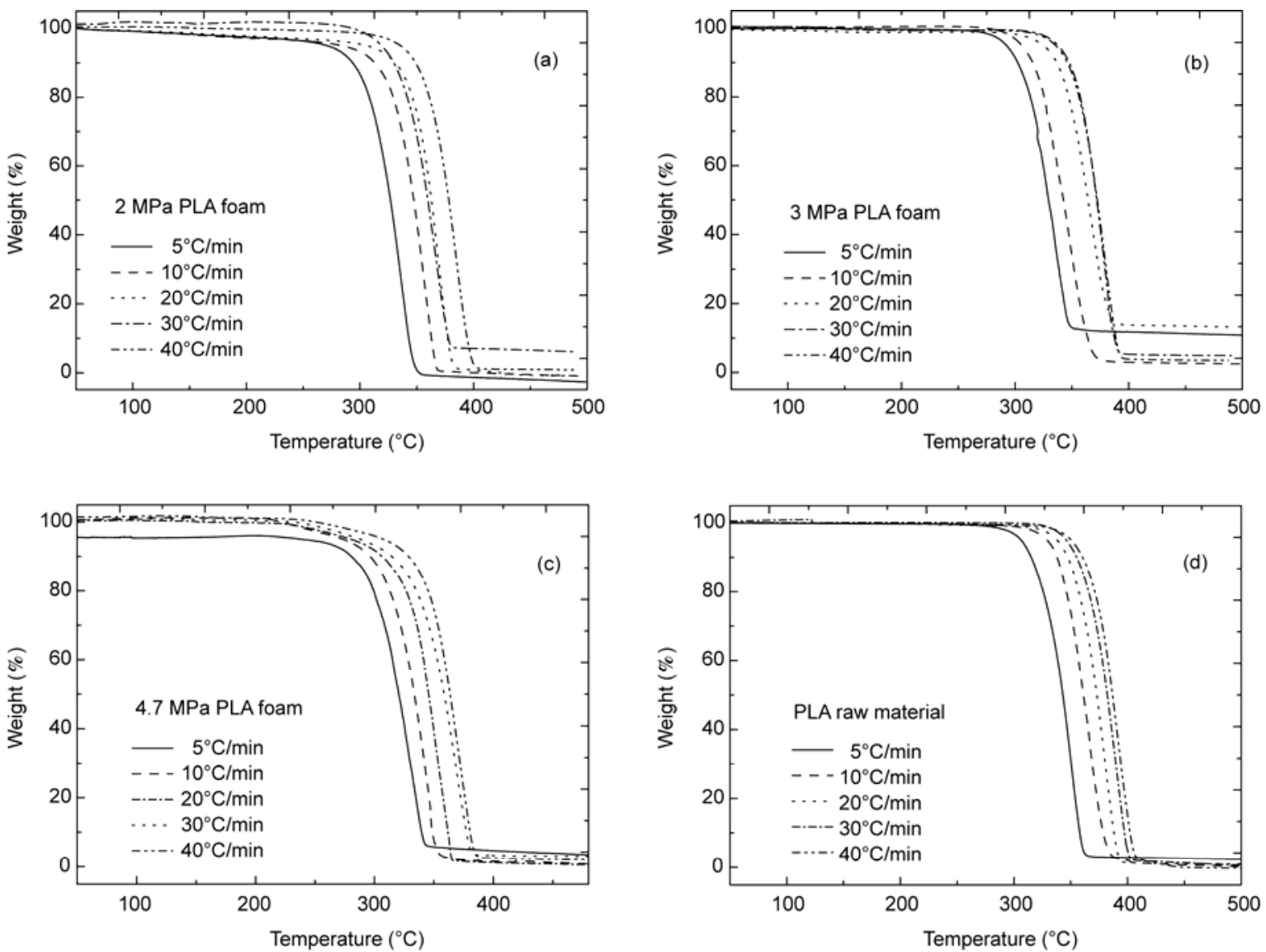

Figure 4 TG curves of the PLA specimens at different heating rates.

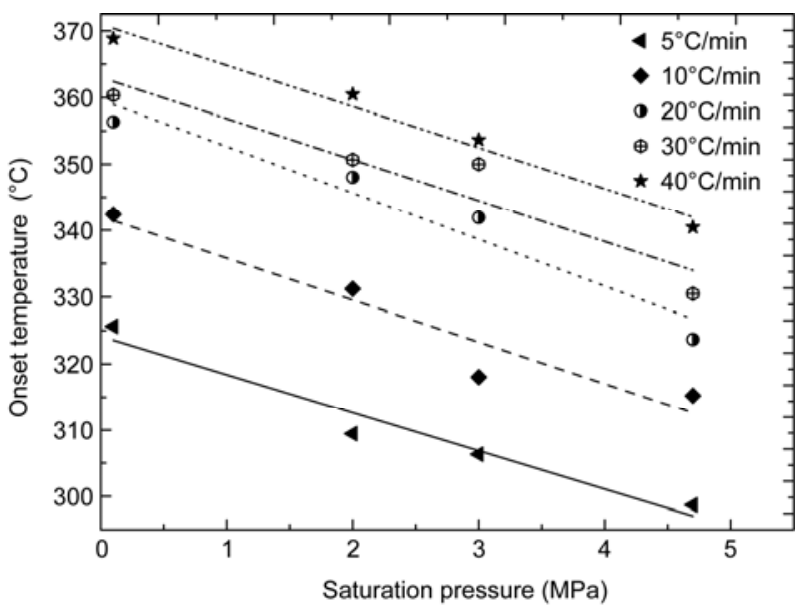

Figure 5 Onset temperatures of the PLA specimens at different heating rates.

saturation pressure, have higher activation energies because of the higher cell density and larger specific surface area, which can effectively reduce the reaction speed and thus prolong lifetime. Moreover, the activation energy of the PLA foam fabricated at $4.7 \mathrm{MPa}$ is close to that of the PLA raw material, because of its high cell density, filled with inert $\mathrm{CO}_{2}$ gas.
The calculated conversion times of the PLA specimens at temperatures $T_{\mathrm{H}}=0,37,100$ and $250^{\circ} \mathrm{C}$ are listed in Table 2, where $R=8.314 \mathrm{~J} /(\mathrm{mol} \mathrm{K})$ and $T$ is the temperature for a decomposition level of $\alpha=5 \%$ at a linear heating rate of $\beta=20^{\circ} \mathrm{C} / \mathrm{min}$. Figure 6 displays the dependence of conversion time for the PLA specimens on temperature from 0 to $300^{\circ} \mathrm{C}$. It can also be concluded that the PLA specimens have good stability at low temperature and the corresponding conversion times are very long under a nitrogen atmosphere. Compared with the PLA foams, the PLA raw material has the slowest degradation rate. At $0^{\circ} \mathrm{C}$, the conversion time for the PLA raw material is about 52 times that of the 4.7 MPa PLA foam, even though their activation energies are similar. Meanwhile, the conversion time for the 4.7 MPa PLA foam is about 16 times that of the 2 MPa PLA foam, because of the difference in cell size and density. As temperature increases, the rate of decrease in conversion time for larger cell size foams is slower than for those with smaller cells. For example, at a body temperature of $37^{\circ} \mathrm{C}$, the PLA raw material and 4.7 MPa PLA foam have conversion times about 242 and 4.5 times that of the 2 MPa PLA foam, respectively. However, at high temperature, the decomposition rates of the PLA specimens are enhanced and the corresponding conversion times decreases rapidly. As listed in Table 2, the conversion times for the 4.7 MPa and 
Table 2 Thermal properties of the PLA specimens

\begin{tabular}{|c|c|c|c|c|c|}
\hline \multirow{2}{*}{\multicolumn{2}{|c|}{ Properties }} & \multicolumn{4}{|c|}{ Specimen } \\
\hline & & PLA raw material & 4.7 MPa PLA foam & 3 MPa PLA foam & 2 MPa PLA foam \\
\hline \multicolumn{2}{|c|}{$\lg A(1 / \mathrm{min})$ Kissinger method } & 20.75 & 22.14 & 18.06 & 15.47 \\
\hline \multicolumn{2}{|c|}{$E(\mathrm{~kJ} / \mathrm{mol})$ Kissinger method } & 151.57 & 151.33 & 133.83 & 124.73 \\
\hline \multicolumn{2}{|c|}{$E(\mathrm{~kJ} / \mathrm{mol})$ Ozawa-Doyle method } & 153.75 & 153.72 & 137.24 & 128.68 \\
\hline \multicolumn{2}{|c|}{ Averaged $E(\mathrm{~kJ} / \mathrm{mol})$} & 152.66 & 152.52 & 135.54 & 126.71 \\
\hline \multirow{4}{*}{$\begin{array}{l}\text { Conversion time for 5\% } \\
\text { decomposition level (min) }\end{array}$} & $0^{\circ} \mathrm{C}$ & $1.429 \times 10^{16}$ & $2.7123 \times 10^{14}$ & $9.1005 \times 10^{13}$ & $1.5992 \times 10^{13}$ \\
\hline & $37^{\circ} \mathrm{C}$ & $6.11 \times 10^{12}$ & $1.15 \times 10^{11}$ & $9.16 \times 10^{10}$ & $2.52 \times 10^{10}$ \\
\hline & $100^{\circ} \mathrm{C}$ & $2.85 \times 10^{8}$ & $5.30 \times 10^{6}$ & $1.28 \times 10^{7}$ & $6.31 \times 10^{6}$ \\
\hline & $250^{\circ} \mathrm{C}$ & 216.45 & 4.01 & 46.73 & 51.85 \\
\hline
\end{tabular}

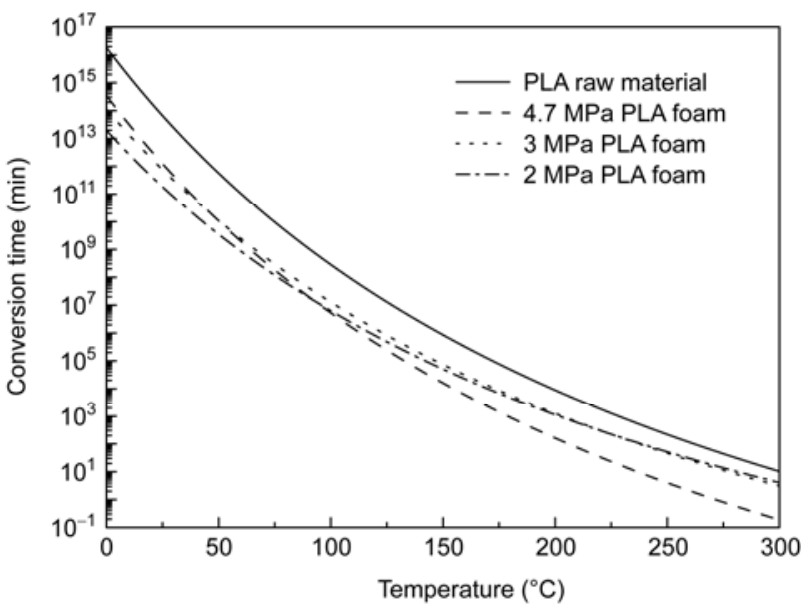

Figure 6 Dependence of conversion time of PLA specimens on temperature for a $5 \%$ decomposition level.

$2 \mathrm{MPa}$ PLA foams are about $5.3 \times 10^{6}$ and $6.3 \times 10^{6} \mathrm{~min}$ at $250^{\circ} \mathrm{C}$, respectively, while they are only 4 and $51 \mathrm{~min}$, respectively, at $300^{\circ} \mathrm{C}$ because of the lower onset temperature of the 4.7 MPa PLA foam.

The conversion time is very long at $37^{\circ} \mathrm{C}$ under a nitrogen environment but the decomposition process would be faster in the biological environment of the human body in the presence of acids, alkalis and enzymes. Nevertheless, the differences in conversion times can reflect the different degradation rates of the PLA specimens in the human body. Through appropriate selection of foaming parameters, the degradation time of the PLA foams can be adjusted from several months to several years [27]. This will be useful for precise PLA foam fabrication, quantitative stability evaluation and estimation of lifetime, to adapt the fabrication process to the unique practical requirements of different tissues in tissue engineering applications.

\section{Conclusions}

This paper presented a method for identifying the decompo- sition kinetics of biodegradable polylactic acid (PLA) foams fabricated using the solid-state foaming technique, enabling a priori cell size and tissue scaffold lifetime estimation. The theoretical and experimental results of cell size distribution showed that saturation pressure was the most important factor for cell nucleation and this determines the cell size and density at a specific foaming temperature. A higher saturation pressure leads to higher gas nucleation in the PLA raw material over a shorter saturation time, which is helpful for enhancing the cell density of the foams. Therefore, smaller PLA foam cell sizes can be achieved at higher saturation pressure. Through TG measurements, the thermal and degradation properties of the PLA specimens were investigated and it was confirmed that the thermal stability of PLA is reduced through the solid-state foaming process and is mainly determined by cell size and density. Based on kinetic analyses of the thermal stability of PLA specimens, it was demonstrated that the activation energy was inversely proportional to cell size and that foams with smaller cell size have a longer degradation time at low temperature $\left(37^{\circ} \mathrm{C}\right)$. In conclusion, the method described for size-dependent property analyses of PLA foams is useful for evaluating the decomposition kinetics and estimating foam lifetime in TES applications. Furthermore, it demonstrates the feasibility of quantitative PLA foam fabrication with appropriate lifetimes that satisfy the requirements of different tissues or organs in TES applications. The solid-state foaming technique in this study created closed-cell foams. Further studies, based on acoustic resonance, cavitation and acoustic micro-jet propulsion technologies, are required to enhance cell interconnectivity and permeability for TES applications through open-cell PLA foam microstructures [21].

This work was supported by the National Basic Research Program of China (2011CB707900), the National Natural Science Foundation of China (10974098), the Natural Science Foundation of Jiangsu Province (BK2009407) and the Doctoral Fund of the Ministry of Education of China (20093207120003). 
tion of articular cartilage. Biomaterials, 2000, 21: 431-440

2 Yoon S N, Tae G P. Biodegradable polymeric microcellular foams by modified thermally induced phase separation method. Biomaterials, 1999, 20: 1783-1790

3 Kothapalli C R, Shaw M T, Wei M. Biodegradable HA-PLA 3-D porous scaffolds: Effect of nano-sized filler content on scaffold properties. Acta Biomater, 2005, 1: 653-662

4 Wang Z, Zhang Z, Zhang J C, et al. Distribution of bone marrow stem cells in large porous polyester scaffolds. Chin Sci Bull, 2009, 54: 2968-2975

5 Yang Y F, Tang G W, Zhao Y H, et al. Effect of degradation of PLGA and PLGA/ $\beta$-TCP scaffolds on the growth of osteoblasts. Chin Sci Bull, 2010, 55: 982-986

6 Huang M S, Coudane J, Li S M, et al. Methylated and pegylated PLA-PCL-PLA block copolymers via the chemical modification of di-hydroxy PCL combined with the ring opening poly-merization of lactide. J Polym Sci Pol Chem, 2005, 43: 4196-4205

7 Mc Neill I C, Leiper H A. Degradation stufies of some polyesters and polycarbonates-1. Polylactide: General features of the degradation under programmed heating conditions. Polym Degrad Stab, 1985, 11: 267-285

8 Lerper H A, Mc Neill I C. Degradation studies of some polyesters and polycarbonates-2. Polylactide: Degradation under isothermal conditions, thermal degradation mechanism and photolysis of the polymer. Polym Degrad Stab, 1985, 11: 309-326

9 Kopinke F D, Mackenzie K. Mechanism aspects of the thermal degradation of poly(lactic acid) and poly( $\beta$-hydroxybutyric acid). J Anal Appl Pyrolysis 1997, 40-41: 43-53

10 Fan Y, Nishida H, Shirai Y, et al. Racemization on thermal degradation of poly(L-lactide) with calcium salt end structure. Polym Degrad Stab, 2003, 80: 503-511

11 Mikos A G, Bao Y, Cima L G, et al. Preparation of poly(glycolic acid) bonded fiber structures for cell attachment and transplantation. J Biomed Mater Res, 1993, 27: 183-189

12 Thevenot P, Nair A, Dey J, et al. Method to analyze three-dimensional cell distribution and infiltration in degradable scaffolds. Tissue Eng, 2008, 14: 1-13

13 Mooney D J, Baldwin D F, Suh N P, et al. Novel approach to fabricate porous sponges of poly(DL-lactic-co-glycolic acid) without the use of organic solvents. Biomaterials, 1996, 17: 1417-1422

14 Hsiao Y L, Maury E E, Desimone J M, et al. Dispersion polymerization of methyl methacrylate stabilized with poly(1,1-dihydroperfluorooctyl acrylate) in supercritical carbon dioxide. Macromolecules, 1995, 28: 8159-8166

15 Singh L, Kumar V, Ratner B D. Generation of porous microcellular 85/15 poly(DL-lactide-co-glycolide) foams for biomedical applications. Biomaterials, 2004, 25: 2611-2617

16 Grizzi L, Garreau H, Li S M, et al. Hydrolytic degradation of devices based on poly(DL-lactic acid) size-dependence. Biomaterials, 1995, 16: 305-311

17 Zou H T, Yi C H, Wang L X, et al. Thermal degradation of poly(lactic acid) measured by thermogravimetry coupled to Fourier transform infrared spectroscopy. J Therm Anal Calorim, 2009, 97: 929-935

18 Agrawal C M, McKinney J S, Lanctot D, et al. Effects of fluid flow on the in vitro degradation kinetics of biodegradable scaffolds for tissue engineering. Biomaterials, 2000, 21: 2443-2452

19 Zhang J, Feng S Y, Ma Q Y. Kinetics of the thermal degradation and thermal stability of conductive silicone rubber filled with conductive carbon black. J Appl Polym Sci, 2003, 89: 1548-1554

20 Wang X, Kumar V, Li W. Low density sub-critical $\mathrm{CO}_{2}$-blown solid-state PLA foams. Cell Polym, 2007, 26: 11-35

21 Wang X, Li W, Kumar V. A method for solvent-free fabrication of porous polymer using solid-state foaming and ultrasound for tissue engineering applications. Biomaterials, 2006, 27: 1924-1929

22 Baldwin D F, Park C B, Suh N P. A microcellular processing study of poly(ethylene terephthalate) in the amorphous and semicrystalline states. Part I: Microcell nucleation. Polym Eng Sci, 1996, 36: 1437-1445

23 Vilar J M G, Rubi J M. Failure of the work-Hamiltonian connection for free-energy calculations. Phys Rev Lett, 2008, 100: 020601

24 Kissinger $\mathrm{H}$ E. Reaction kinetics in differential thermal analysis. Anal Chem, 1969, 41: 2060-2069

25 Ozawa T. A new method of analyzing thermogravimetric data. Bull Chem Soc Jpn, 1965, 38: 1881-1886

26 Doyle C D. Estimating thermal stability of experimental polymers by Empirical thermogravimetric analysis. Anal Chem, 1961, 33: 77-79

27 Lu L, Garcia C A, Mikos A G. In vitro degradation of thin poly(DLlactic-co-glycolic acid) films. J Biomed Mater Res, 1999, 46: 236244

Open Access This article is distributed under the terms of the Creative Commons Attribution License which permits any use, distribution, and reproduction in any medium, provided the original author(s) and source are credited. 